\title{
Sex Differences in Cocaine-Stimulated Motor Behavior: Disparate Effects of Gonadectomy
}

\author{
Q. David Walker, Ph.D., Jose Cabassa, B.S., Karly A. Kaplan, B.S., Shih-Tzung Li, B.S., \\ Jennifer Haroon, B.S., Hilmar A. Spohr, M.S., and Cynthia M. Kuhn, Ph.D.
}

Sex differences in biological substrates of drug use and addiction are poorly understood. The present study investigated sexual dimorphisms in motor behavior following acute cocaine administration (10,20, or $40 \mathrm{mg} /$ $\mathrm{kg}$, i.p.). Cocaine increased stereotypy rating, horizontal and vertical activity in both sexes, and effects were always greater in females than males. A population analysis using data from multiple experiments indicated that horizontal activity scores were normally distributed in males but not in females. Gonadectomy induced disparate effects on cocaine-stimulated motor behavior. Population analysis indicated that castrated males exhibited more horizontal activity and stereotypy than shams. Ovariectomy did not affect cocaine-stimulated stereotypy but did attenuate horizontal activity in a subset of rats that had not been vaginally lavaged. In summary, gonadectomy effects were sex and behavioral topography specific and indicate that activational effects of gonadal hormones partially mediate the robust sex differences in cocaine-stimulated open-field behavior.

[Neuropsychopharmacology 25:118-130, 2001] (C) 2001 American College of Neuropsychopharmacology. Published by Elsevier Science Inc.
KEY WORDS: Locomotion; Rearing; Stereotypy; Gonadal hormones; Psychostimulant

Little is known about sex differences in biologic substrates of drug taking and addiction. However, an emerging literature documents that sex differences in the behavioral responses to addictive drugs exist in humans. A sex difference in human affective responses to cocaine has been reported in one study in which females reported more nervousness than males following intranasal cocaine (Kosten et al. 1996). Lukas and coworkers (1996) showed that cocaine induced similar cardiovascular and affective responses in men and

From the Department of Pharmacology, Duke University Medical Center, Durham, NC.

Address correspondence to: Dr. Cynthia M. Kuhn, Department of Pharmacology, 401 Bryan Research Building, Box 3813, Duke University Medical Center, Durham, NC 27710. women, although plasma concentrations of cocaine were lower in women. In a laboratory setting, cocaine cues induced more drug craving in female than male addicts (Robbins et al. 1999). These results suggest that women may be more sensitive to cocaine than men. In fact, women begin using cocaine and enter treatment at earlier ages than men (Griffin et al. 1989; Mendelson et al. 1991) and have more severe cocaine use at intake than men (Kosten et al. 1993).

Sex differences in spontaneous and drug-stimulated behavior have been carefully studied in animals. Probably the most robust sex difference in behavior is the observation that female rats exhibit more running wheel activity than males (for review see Beatty 1979). Female rats are also often reported to be more active than males in open-field situations (Beatty 1979). These sex differences in basal or non-stimulated behavior are likely related to the reported sex differences in open-field behavior following psychomotor stimulant administration (van Hartesveldt and Joyce 1986). Amphetamine is 
particularly well known for producing greater behavioral effects in female rats following acute administration (Schneider and Norton 1979; Savageau and Beatty 1981; Becker et al. 1982; Camp et al. 1986; Camp and Robinson 1988a). Acute cocaine administration has also been reported to induce greater behavioral effects in female rats (van Haaren and Meyer 1991; Haney et al. 1994; Bowman and Kuhn 1996) and in mice (Sershen et al. 1998). However, in other reports, sex differences in acute cocaine-stimulated motor behavior were not observed in naïve Sprague-Dawley rats (Craft and Stratman 1996) and in three other rat strains (Cailhol and Mormede 1999). Thus, better evidence of sex-differences in acute behavioral effects in intact animals exists for amphetamine than cocaine.

Gonadal and especially ovarian hormones have been investigated as likely modulators of these sex differences in behavior. Ovarian hormone effects on stimulant responses are complex, as ovariectomy and estrous cycle studies sometimes provide apparently contradictory results (van Hartesveldt and Joyce 1986). Two studies (Savageau and Beatty 1981; Camp and Robinson 1988b) found that ovariectomy did not affect amphetamine-stimulated stereotypy, while only one showed effects on locomotion (Savageau and Beatty 1981). Despite this absence of ovariectomy effect on stereotypy, the intensity of stereotyped behavior following amphetamine was greater during estrus (Becker and Cha 1989). Female rats in estrus also make more rotations following amphetamine (Becker and Beer 1986) or electrical stimulation of the medial forebrain bundle (Robinson et al. 1981, 1982) than ovariectomized rats. Cocaine effects on locomotion and stereotypy are also greater in female rats in estrus (Quinones-Jenab et al. 1999). Orchidectomy effects on behavioral responses to stimulants are even less understood. Camp and Robinson (1988b) and Beatty et al. (1982) reported that castration increased amphetamine-induced stereotypy but not locomotion.

A consistent picture about the role of gonadal steroids on behavioral responses to stimulants has been elusive. Different behavioral strategies and paradigms used by different authors and the absence of males in many studies have complicated the issue. A better description of biologic sex differences in acute cocainestimulated behavior is vital to understanding individual vulnerabilities in the establishment of drug-taking because the degree of "liking" of the initial cocaine exposure is significantly associated with subsequent cocaine taking habits (Haertzen et al. 1983). Therefore, we conducted the present studies to compare directly the effects of male and female gonadectomy on sex differences in acute cocaine-stimulated open-field behavior. This work examined multiple components of motor activity in the open field: horizontal and vertical movements and integrated observational ratings of be- havioral activation. Pooling data from multiple experiments to form population databases led to novel observations of sex differences in individual responsiveness to cocaine.

\section{METHODS}

\section{Subjects}

Adult male and female Sprague-Dawley rats were purchased from Charles River Laboratories (Raleigh, NC). They were segregated by sex and were housed in plastic cages under a 12:12 light: dark cycle with lights on at $0600 \mathrm{hr}$. Food and water were provided ad libitum. The animal supplier performed bilateral ovariectomy, castration or sham surgery when rats were 60 days of age.

Rats were tested two to three weeks after shipment on average. Animals were moved to the testing facility and weighed the day before observations. Animal care was in accordance with the Guide for the Care and Use of Laboratory Animals (NIH publication 865-23, Bethesda, MD) and approved by the Institutional Animal Care and Use Committee.

\section{Estrous Cycle Monitoring}

Estrous cycle stage was monitored in several experiments (see Experiments section) by analysis of cell types in vaginal lavages. Daily vaginal lavages were collected in the morning for at least eight consecutive days prior to testing and allowed to dry on microscope slides. Slides were then fixed with ethanol and stained with toluidine blue. Identification of cell types was made microscopically according to published methods (Long and Evans 1922). Lavage was used to verify lack of cycling in ovariectomized rats in certain experiments (Cooper et al. 1993).

\section{Behavioral Apparatus}

Initial studies of sex differences and gonadectomy in cocaine effects used Opto-Varimex photocell chambers (Columbus Instruments, Columbus, $\mathrm{OH}$ ). Later experiments were performed in similar photocell devices from a different supplier (San Diego Instruments, Inc., San Diego, CA). The two devices were comprised of open plexiglass arenas with wood chip bedding on the floor. Horizontal activity (locomotion) and vertical activity (rearing) were determined from interruptions of photobeams spaced one inch apart in both devices. Photocell interruptions were also recorded at $5 \mathrm{~min}$ intervals. Data from the later devices were recorded on a computer using software from the manufacturer. Vertical activity is reported as the number of photocell interruptions. The horizontal distance traveled in inches is reported as horizontal activity. 


\section{Behavioral Methods}

Assignment to test chambers was counterbalanced across and within days with respect to sex, cocaine dose, and surgical status. Experiments were conducted only during the light cycle from 0900 to 1500 hours. Rats were allowed to habituate to the chambers for 40 minutes. Cocaine $\mathrm{HCl}$ was prepared fresh in $0.9 \%$ saline and either the saline vehicle $(1 \mathrm{ml} / \mathrm{kg})$ or cocaine was injected i.p. In the initial dose response and gonadectomy experiments, the topography of behavior was assessed simultaneously with locomotor activity by recording the occurrence of inactivity, rearing, grooming, locomotion, sniffing, continuous sniffing, and stereotypy during three observation periods consisting of fifteen seconds each, every $5 \mathrm{~min}$, beginning $5 \mathrm{~min}$ after dosing. Stereotypy included head weaving or bobbing, patterned locomotion, paw treading, and dyskinesia. A single observer, blind to the drug treatment, watched all the rats in individual experiments. For each of the three observation periods, a summed stereotypy score modified from that of Gifford and Johnson (1992) was assigned according to the behaviors observed. These three scores were then averaged to obtain a score for that minute. The scoring system was: 1 , inactive; 2 , grooming or locomotion or sniffing or rearing; 3 , sniffing with locomotion and/or rearing, or continuous sniffing; 4, continuous sniffing with continuous motion; 5 , frequent stereotyped movements with locomotion; 6 , almost continuous stereotyped movements, restricted to one place in the cage.

\section{Experiments}

The effects of sex and gonadal hormones on cocainestimulated behavior were examined in several experiments. The initial experiment used naïve, intact males and intact, non-lavaged females. Horizontal motor activity (locomotion) was determined in the Opto-Varimex devices following i.p. injection of either the saline vehicle, 10,20 , or $40 \mathrm{mg} / \mathrm{kg}$ cocaine. Simultaneously, these
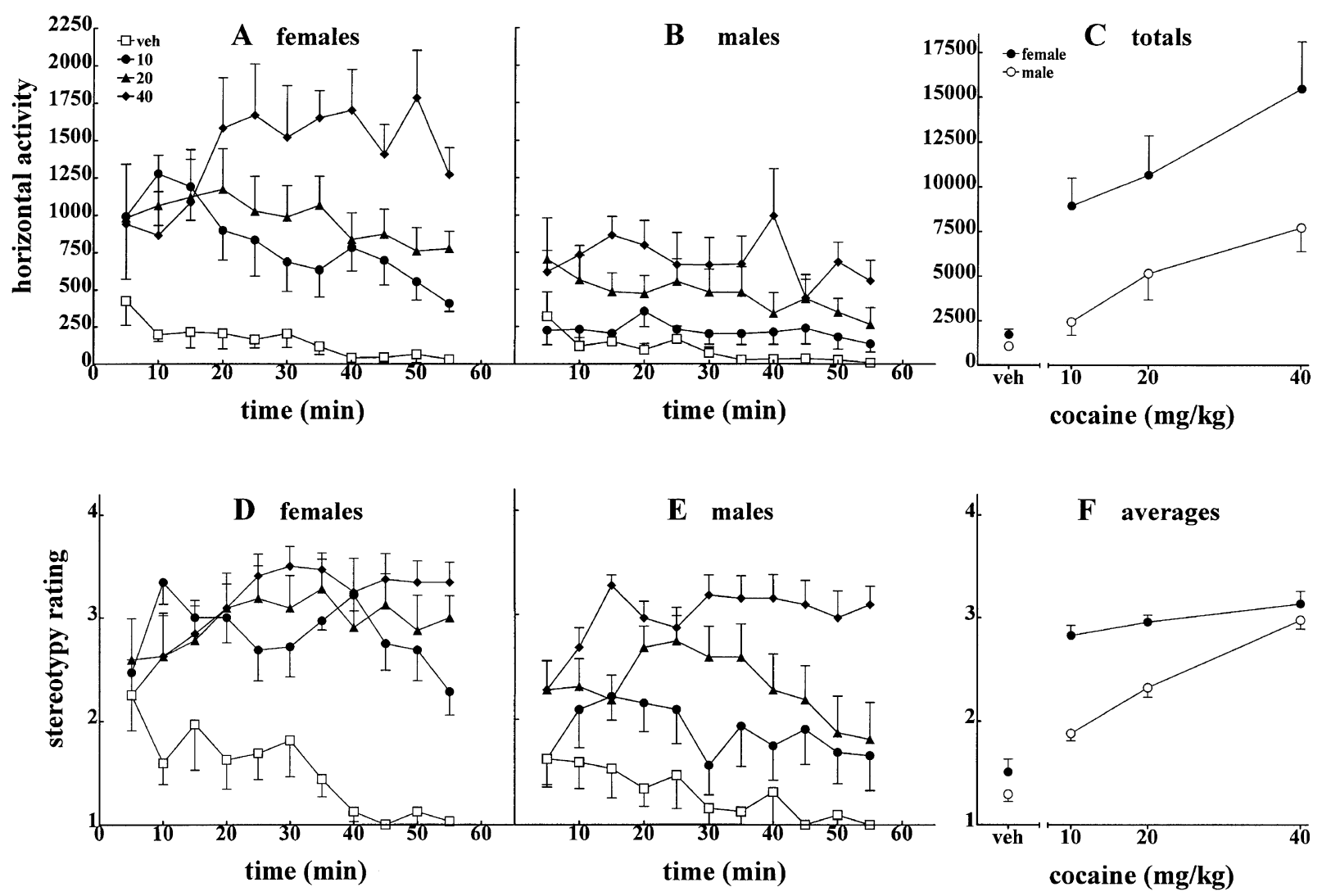

Figure 1. Effect of cocaine on horizontal activity (top panels) and stereotypy rating (bottom panels) in intact male and female rats ( $n=8$ /group). Horizontal activity (A and $\mathbf{B}$ ) and stereotypy data (D and $\mathbf{E}$ ) in 5-min intervals are shown following administration of the saline vehicle, 10,20 , or $40 \mathrm{mg} / \mathrm{kg}$ cocaine. Horizontal activity in all intervals of the session was summed to show the cocaine dose-response effect on total horizontal activity in C. Stereotypy ratings in all 5 min-intervals were averaged and are shown in F. Group means + / - standard errors are shown in this and all figures. Error bars are subsumed by the symbols in some cases. 

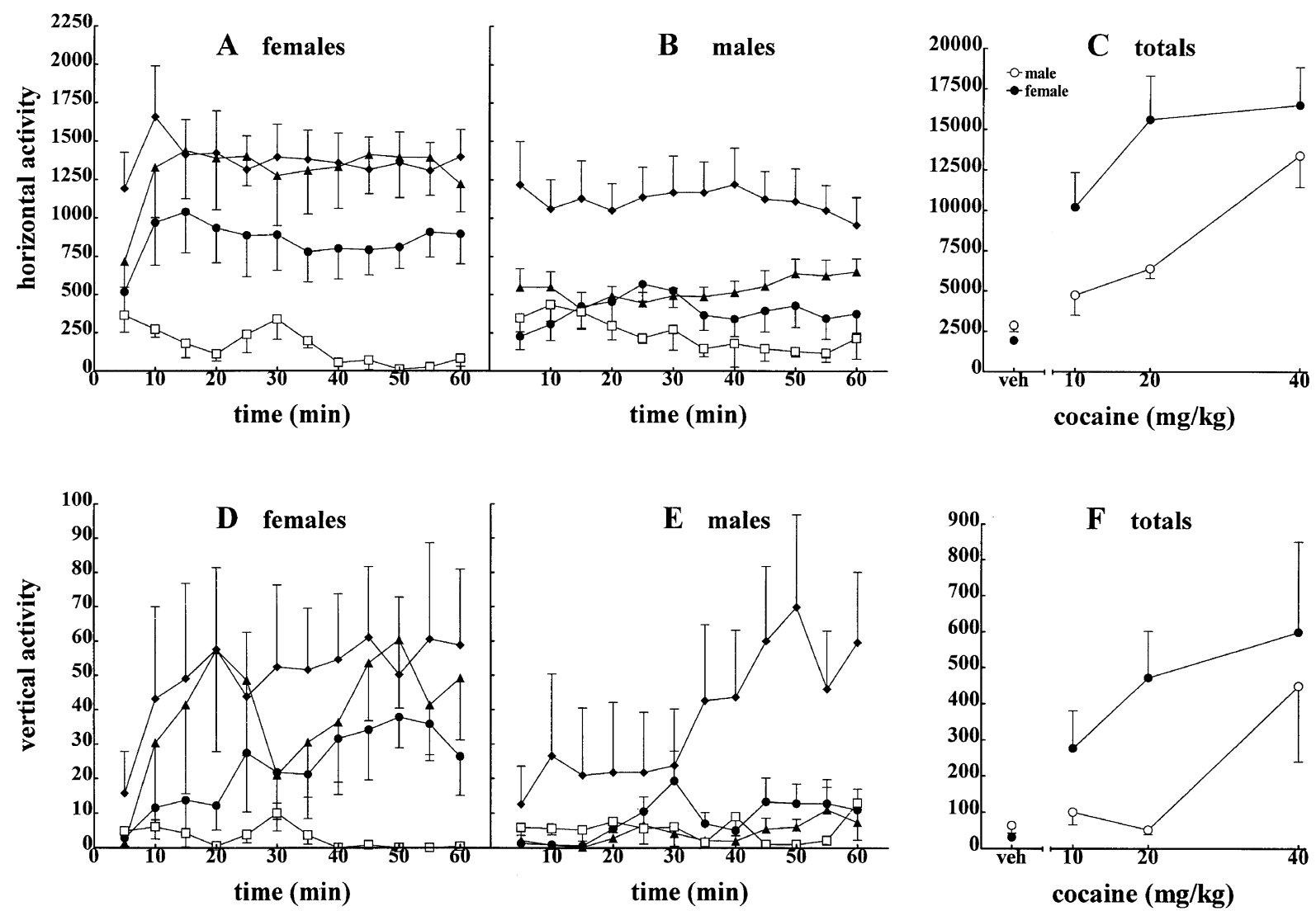

Figure 2. Effect of cocaine on horizontal and vertical activity in intact male and female rats $(n=5$ or $6 /$ group). Horizontal (A and B) and vertical activity data (D and E) in 5-min intervals are shown following administration of the saline vehicle, 10,20 , or $40 \mathrm{mg} / \mathrm{kg}$ cocaine. As in Figure 1, cocaine dose-response effects on total horizontal (C) and vertical (F) activity are also shown.

animals were observed to determine stereotypy ratings (Figure 1). We replicated this initial dose response experiment in different activity monitoring devices that included both horizontal and vertical photobeam arrays (Figure 2).

Castration of adult male and female rats was directly compared in a dose-response experiment (Figure 3). Castrated and sham-castrated male and female rats of the same age were injected with either the saline vehicle, 10,20 , or $40 \mathrm{mg} / \mathrm{kg}$ cocaine and horizontal and vertical motor activity was recorded simultaneous with observer-rated stereotypy.

All the horizontal activity data resulting from vehicle and $10 \mathrm{mg} / \mathrm{kg}$ cocaine treatments from 19 different experiments were combined for a population-style analysis. Eleven of the 19 experiments included both male and female rats, five used only females, and three used only males. Six of the 19 total experiments included sham-operated and gonadectomized females and males. In addition to these six experiments, three included ovariectomized and sham-ovariectomized rats exclusively, and one used only castrated and sham-cas- trated males. The nine experiments that compared the effects of $10 \mathrm{mg} / \mathrm{kg}$ cocaine in sham and ovariectomized females were subsequently categorized according to whether or not the rats had been vaginally lavaged. Cocaine dose-response relationships were determined for stereotypy and horizontal activity in sham and castrated males in three experiments and these were combined to examine castration effects in a population.

\section{Reagents}

Cocaine $\mathrm{HCl}$ was obtained from NIDA and the Research Triangle Institute (Research Triangle Park, NC). Cocaine solutions were prepared fresh daily in $0.9 \%$ saline.

\section{Data Analysis}

Motor activity (horizontal and vertical) and stereotypy data are shown as the mean + SEM in 5-min intervals beginning immediately after injection. Activity session 

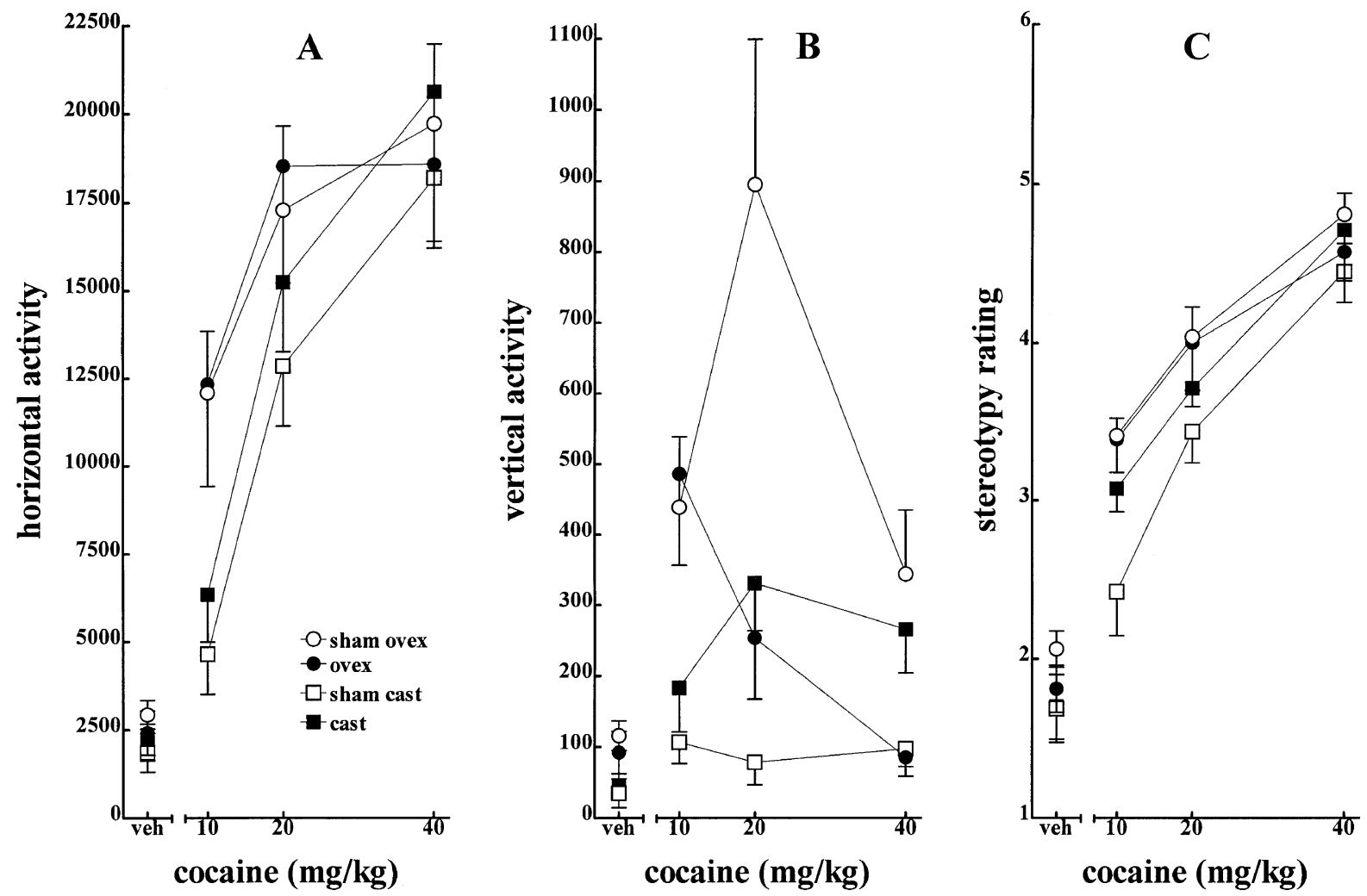

Figure 3. Effect of cocaine on motor behavior in sham $(n=16)$ and gonadectomized $(n=8)$ male and female rats. Cocaine dose-response effects on total horizontal (A) and vertical (B) activity and average stereotypy score (C) during a one hour session are displayed. All female rats had been vaginally lavaged to monitor estrous cycle stage and determine the efficacy of the ovariectomy surgery.

totals and average stereotypy scores of all 5 min intervals were also calculated and shown. The effects of cocaine and sex on motor behavior and stereotypy were analyzed using two-way ANOVA with repeated measures on trial (five minute intervals in Figures 1 and 2: A, B, D, E). The effects of sex, castration and cocaine were determined using three-way ANOVA (sex $\times$ surgery $\times$ dose) with repeated measures on trial (Figure 3 ). Repeated measures ANOVA used Geisser-Greenhouse adjustments of probability levels for F-tests. ANOVA's were performed using NCSS 2000 software (NCSS, Inc, Kaysville, UT).

Scattergrams and relative frequency histograms were produced from populations of horizontal activity values using Prism 3.0 (Graphpad Software, Inc., Carlsbad, CA). This software was also used to test for deviations from Gaussian distribution using the Kolmogorov-Smirnov test. Distributions were said to be significantly non-Gaussian when $p<.05$. Sex and gonadectomy effects in populations were analyzed individually using Student's T-test. When distributions were found to be significantly non-Gaussian the non-parametric Mann-Whitney test was used. Differences were considered significant when $p<.05$.

\section{RESULTS}

\section{Acute Behavioral Effects of Cocaine in Intact Rats}

Cocaine increased horizontal activity in all rats and these effects were greater in female rats. Figure 1 shows time course (A, B) and session totals (C) for horizontal activity. Horizontal activity in vehicle-treated rats gradually decreased or habituated throughout consecutive 5-min intervals of the test session (Figure 1: A and B). The sex difference in cocaine-stimulated activity, though apparent over the entire dose range, is most clear at the lowest dose, $10 \mathrm{mg} / \mathrm{kg}$. At this dose locomotor stimulation relative to the vehicle treatment was marked in females and negligible in males. Two-way ANOVA indicated significant main effects on horizontal activity for cocaine $(\mathrm{F}(3,56)=15.6, p<.0001)$ and $\operatorname{sex}(\mathrm{F}(1,56)=22.4, p=.001)$ but the dose by sex interaction was not significant $(p=.11)$. Horizontal activity varied across the test session as indicated by the significant effect of the repeated factor, trial $(\mathrm{F}(10,560)=2.85$, $p=.002$ ).

Figures $1 \mathrm{D}, 1 \mathrm{E}$, and $1 \mathrm{~F}$ show that stereotypy ratings were greater in female rats $(\mathrm{F}(1,56)=16.2, p=.001)$. Sex differences again were most apparent for stereo- 
typy at the low dose of cocaine (Figure 1F). Cocaine increased stereotypy rating in a dose-related fashion in males, and at the highest dose males were comparable to females. Few rats of either sex transitioned into intense stereotyped behavior. Two-way ANOVA indicated that cocaine significantly increased stereotypy rating $(\mathrm{F}(3,56)=33.1, p<.001)$, but no interaction of dose and sex was found $(p=.08)$. Trial also exerted a significant effect on stereotypy $(\mathrm{F}(10,560)=3.33, p<$ $.001)$.

The initial dose-response activity experiment was replicated in a different testing apparatus that provided both horizontal and vertical motor activity data. Time course data (Figures 2A and 2B) and session totals (Figure $2 \mathrm{C}$ ) show that cocaine increased horizontal activity overall $(\mathrm{F}(3,33)=19.5, p<.001)$. Females exhibited more horizontal activity than males $(\mathrm{F}(1,33)=12.3, p=$ $.001)$ and in this experiment, a significant interaction of sex and dose was observed $(\mathrm{F}(3,33)=3.11, p=.04)$. The effect of trial did not reach statistical significance $(p=.09)$.

Figure $2(C, D, E)$ shows the effect of cocaine on rearing behavior in male and female rats. Cocaine increased rearing overall $(\mathrm{F}(3,33)=4.8, p=.007)$ and females reared more than males $(\mathrm{F}(1,33)=3.95, p=.05)$. No interaction of sex and dose was found $(p=.39)$. The effect of trial was significant for vertical activity $(\mathrm{F}(11,363)=$ $5.27, p<.001)$.

\section{Effect of Ovariectomy and Castration}

Figure 3 shows cocaine dose-response effects in ovariectomized, castrated, and sham-gonadectomized rats. Cocaine significantly increased all three measures of behavior in this experiment. Figure 3A indicates that cocaine induced dose-related increases in horizontal activity $(\mathrm{F}(3,144)=51.3, p<.001)$ and that horizontal activity was greater in all female than all male rats $(\mathrm{F}(1$, $144)=6.79, p=.01)$. Figure $3 \mathrm{~B}$ shows that cocaine increased rearing behavior $(\mathrm{F}(3,139)=5.59, p<.001)$ although not in a dose-related manner like for horizontal activity. Rearing was also greater in female rats overall $(\mathrm{F}(1,139)=11.1, p=.002)$. Figure $3 \mathrm{C}$ shows that cocaine increased stereotypy scores in all rats $(\mathrm{F}(3,139)=$ 19.3, $p=.001)$ and female rats had higher stereotypy scores $(\mathrm{F}(1,139)=37.9, p<.001)$.

The sex differences observed in the prior experiments for horizontal activity, rearing, and stereotypy also existed between sham ovariectomized and sham castrated rats. Two-way ANOVA (sex $\times$ dose) indicated that female shams exhibited more horizontal activity $(\mathrm{F}(1,88)=6.6, p=.02)$, vertical activity $(\mathrm{F}(1,85)=$ $15.6, p=.0002)$, and stereotypy $(\mathrm{F}(1,87)=21.8, p<.001)$ than male shams.

Of the three indices of open field behavior, horizontal activity was least affected by gonadectomy. Neither ova- riectomy nor castration altered horizontal activity significantly. In contrast, gonadectomy produced disparate effects in males and females with regard to both vertical activity and stereotypy. ANOVA indicated significant interactions of gonadectomy and sex for vertical activity $(\mathrm{F}(1,139)=8.63, p=.004)$ and stereotypy $(\mathrm{F}(1,144)=$ $13.6, p<.001)$. Rearing was less in ovariectomized relative to sham females $(\mathrm{F}(1,87)=5.5, p=.02)$ and greater in castrated rats relative to sham males $(\mathrm{F}(1,52)=16.1$, $p<.001)$. Stereotypy rating was higher in castrated than sham-castrated rats $(\mathrm{F}(1,55)=5.61, p=.02)$, but ovariectomy did not affect stereotypy score $(p=.28)$.

\section{Population Analysis of Sex Differences}

Data from all experiments using vehicle and $10 \mathrm{mg} / \mathrm{kg}$ cocaine were combined to examine further sex and individual differences in behavioral responses. Horizontal activity values for all intact male and female rats used in 19 different experiments have been plotted in Figure 4 as scattergrams, group averages, and relative histograms. This analysis included 246 male rats and 344 females. The scattergram in $4 \mathrm{~A}$ shows that most horizontal activity values from males administered 10 $\mathrm{mg} / \mathrm{kg}$ cocaine are under 7500 and densely clustered. Only a relatively few rats in this group exhibited activity values above 7500 . In contrast, the cocaine-treated female values show a much greater range and a significant fraction of the population is higher than the high responding males. Group averages confirm the trends observed in the cocaine scattergram and extend it to the saline data also. Figure 4B indicates that activity in females following both saline and $10 \mathrm{mg} / \mathrm{kg}$ cocaine is greater than the respective male groups ( $p^{\prime} s<.001$ by Mann-Whitney tests).

The robust sex differences in horizontal activity shown in Figure 4B reflect significant sex differences in each individual experiment. Both relative frequency histograms revealed similar distribution patterns in Figures $4 \mathrm{C}$ and D. Male horizontal activity values following injection of either saline or $10 \mathrm{mg} / \mathrm{kg}$ cocaine exhibited typical "bell-shaped" distributions. A larger proportion of high responders was seen in both female populations. These high responding females significantly skewed both distributions of female activity so that they were not normally distributed $(p=.05)$.

\section{Population Analysis of Ovariectomy Data}

Populations of horizontal activity scores from nine separate experiments using ovariectomized and shamovariectomized females injected with $10 \mathrm{mg} / \mathrm{kg}$ cocaine were also analyzed. These activity values were segregated according to whether the rats had previously been vaginally lavaged and are shown separately in each panel of Figure 5. Ovariectomy did not alter co- 

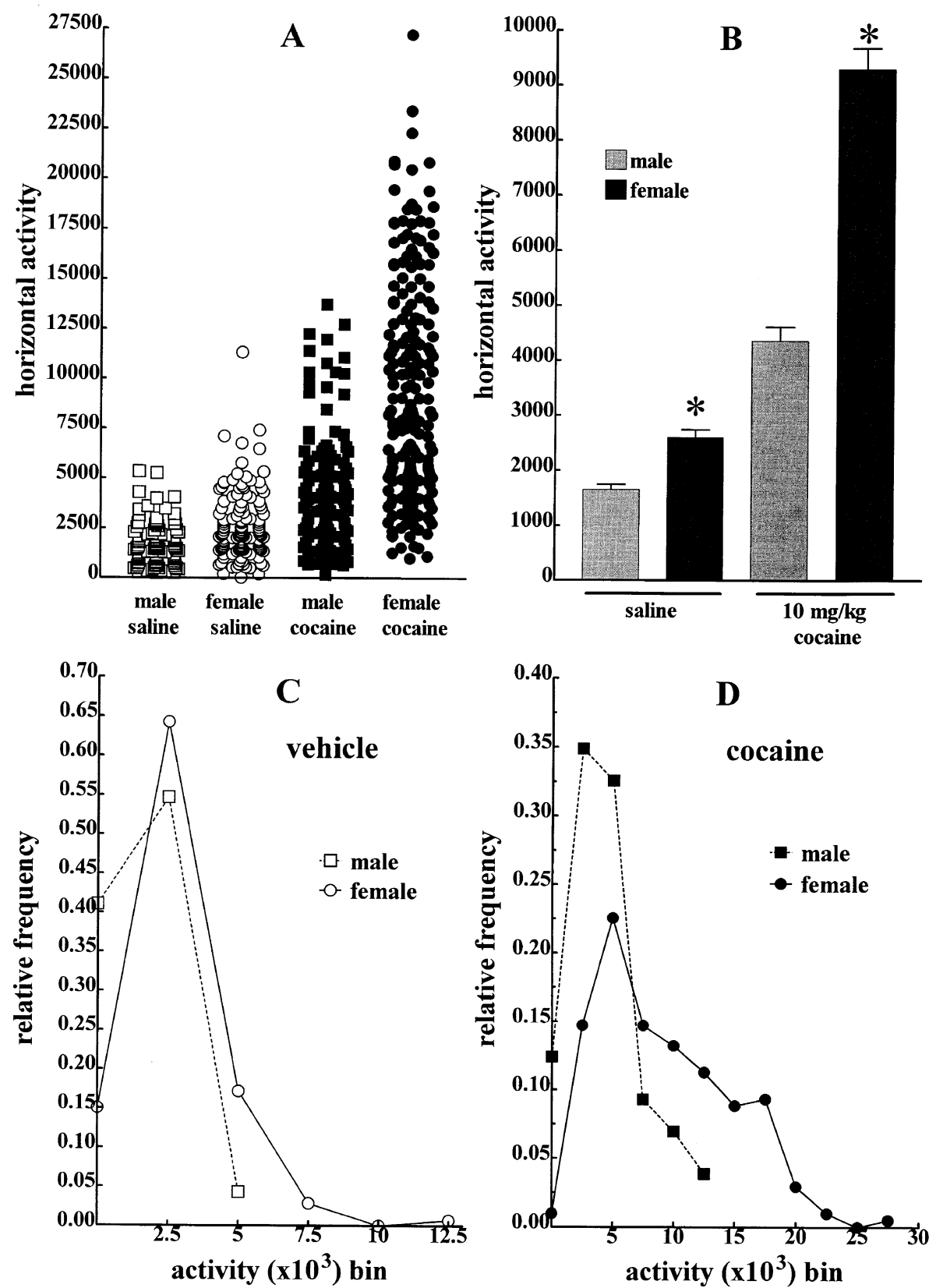

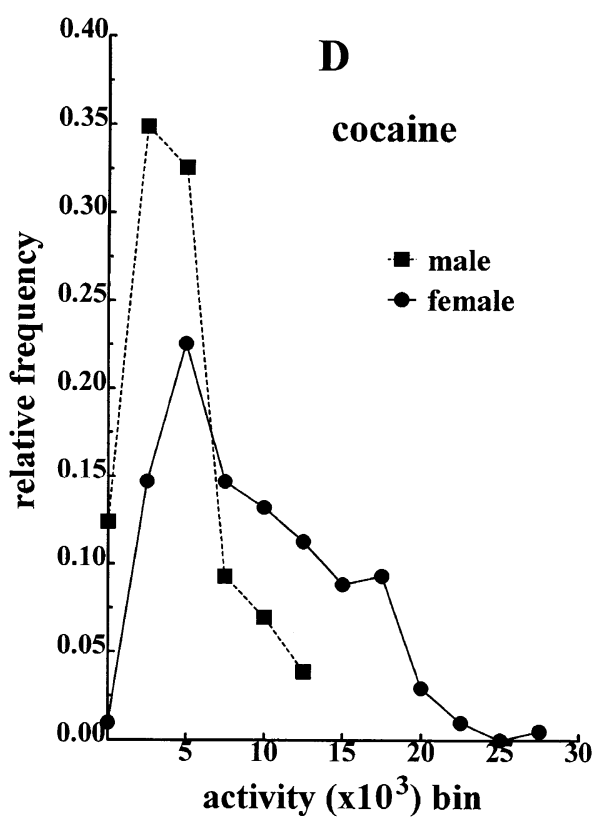

Figure 4. Population analysis of sex differences in horizontal activity following saline or 10 $\mathrm{mg} / \mathrm{kg}$ cocaine injection. Panel A is a scattergram or column graph of all the horizontal activity values in this database. Panel B shows the group means $+/-$ standard errors of the same data sets in panel A. These same data sets are also shown as relative frequency histograms in the bottom panels. Panel $\mathrm{C}$ shows data from male $(n=117)$ and female $(n=140)$ rats injected with the saline vehicle and panel $\mathbf{D}$ shows data from male $(n=129)$ and female $(n=204)$ rats injected with $10 \mathrm{mg} / \mathrm{kg}$ cocaine. The bin size for both histograms is 2500 (inches) and the center of the first bin is at $0 .{ }^{*}$ significantly different than males given the same treatment $(p<.001)$. caine-stimulated horizontal activity in five experiments using lavaged rats (t-tests, $p^{\prime} s=034-0.94$ ). Three of four experiments that tested the effect of ovariectomy in non-lavaged rats reported that ovariectomy significantly decreased cocaine-stimulated horizontal activity $(p<.05)$. The fourth experiment, in which the effect of ovariectomy did not reach statistical significance $(p=$ $.092)$, had the smallest sample size $(n=6)$ and therefore least power of these four. No significant differences were found between any groups following vehicle treatment and therefore were not shown.

A scattergram of all the cocaine-stimulated horizontal activity data from these nine ovariectomy ex- periments is shown in Figure 5A. In the lavaged ovariectomized and sham females groups, a few "high responding" values $(>15,000)$ were widely dispersed. No differences were obvious between these two columns of data and their distributions were very similar (Figure 5C). A larger fraction of high responding values from the non-lavaged sham rats was tightly clustered between 15,000 and 20,000 (Figure 5A). In sharp contrast, only two individuals in the non-lavaged ovariectomized group were in the same range. Likewise, the distribution of horizontal activity values from non-lavaged ovariectomized rats appeared to have a different shape than that recorded in the corresponding sham fe- 

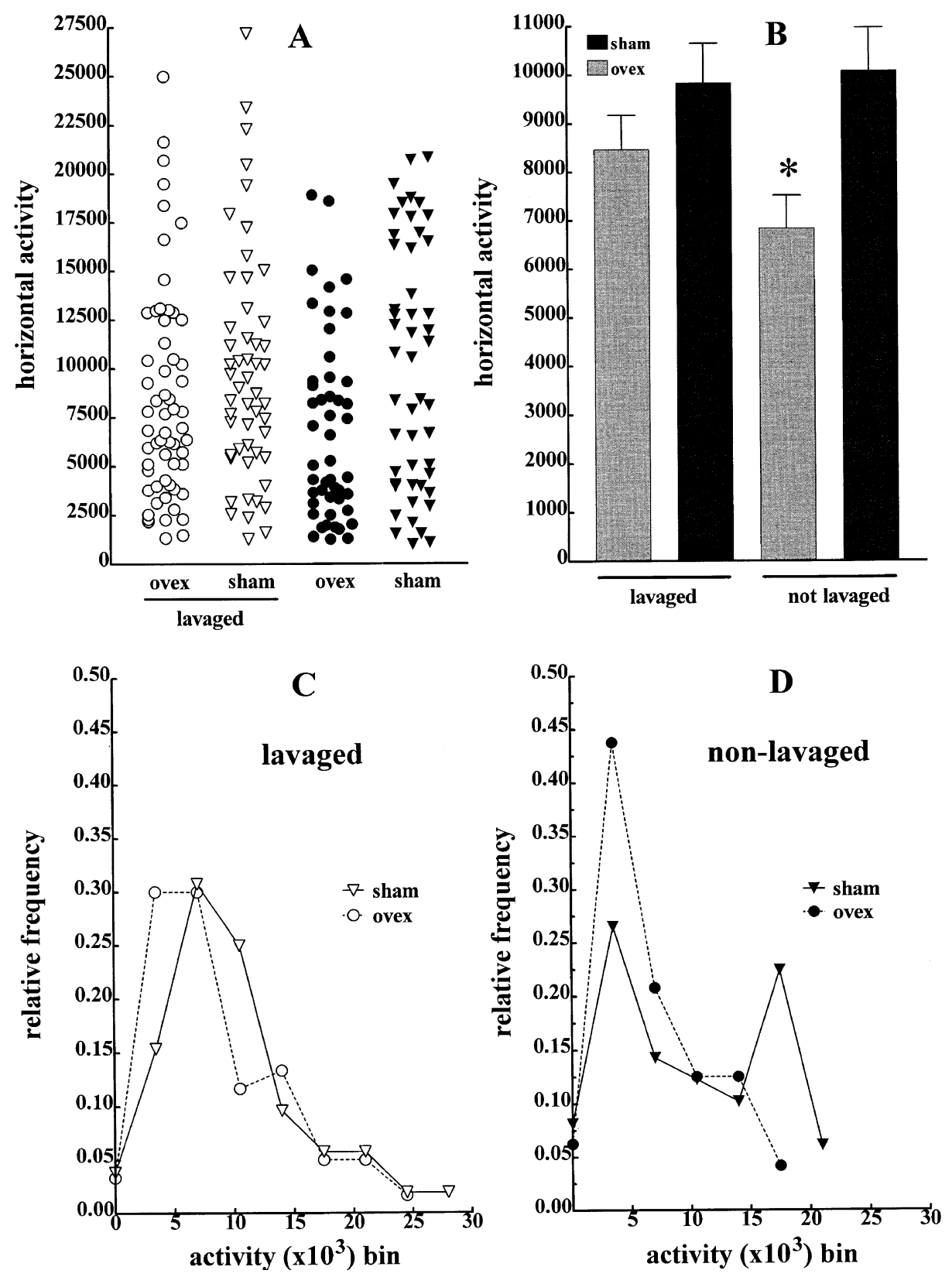

Figure 5. Population analysis of ovariectomy effects on cocaine-stimulated horizontal activity. Panel A is a column graph of all the horizontal activity values in this database segregated by surgical and lavage status. Group means +/standard errors of these four data sets are shown in panel $\mathbf{B}$. These data sets are also shown as relative frequency histograms in the bottom panels. Panel C shows data from lavaged ovariectomized $(n=60)$ and sham-ovariectomized $(n=$ 52) injected with $10 \mathrm{mg} / \mathrm{kg}$ cocaine and panel D shows similar data from non-lavaged ovariectomized $(n=48)$ and sham-ovariectomized $(n=49)$ rats. The bin size for both histograms is 3500 (inches) and the center of the first bin is at 0 . * significantly different than nonlavaged sham ovariectomized females $(p=.001)$. males (Figure 5D). Relative distributions of cocaine responses in non-lavaged rats suggest that ovariectomy selectively attenuated a high responding sub-population as an additional $22 \%$ of the sham, relative to the ovariectomized, population had high activity values (above the 14,000 bin; Figure 5D).

Group averages of these data (Figure 5B) indicate that horizontal activity in non-lavaged ovariectomized rats is less than non-lavaged shams $(\mathrm{t}=2.89$, $\mathrm{df}=$ $95, p=.005)$. A significant decrease in horizontal activity in ovariectomized rats treated with cocaine was also determined when lavaged and non-lavaged data were considered together $(\mathrm{t}=2.85, \mathrm{df}=199, p=.0048$, com- bination bars not shown). Ovariectomy did not affect horizontal activity in lavaged rats $(p=.2)$.

\section{Population Analysis of Castration Data}

A population-style analysis was also performed to determine the effects of male castration on cocaine-stimulated behavior by combining data from three experiments (including the single castration experiment previously described). Each investigated the effects of vehicle, 10, 20, and $40 \mathrm{mg} / \mathrm{kg}$ cocaine on horizontal activity and behavioral activation in castrated and shamoperated males ( $n=25-27$ /group). Because these male 


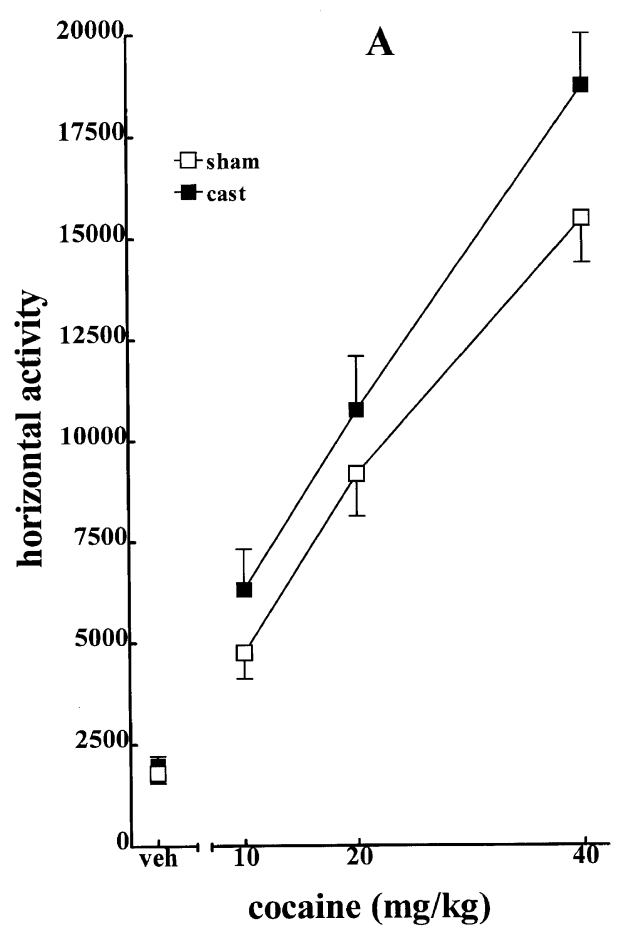

populations of $10 \mathrm{mg} / \mathrm{kg}$ cocaine values were too small for distribution analysis, the population analysis considered dose-response effects on both horizontal activity and stereotypy. These data were analyzed by twofactor ANOVA (surgery $\times$ dose) and are shown in Figure 6 . The population analysis indicated that castrated rats ambulated more than sham males overall $(\mathrm{F}(1,199)=$ $5.78, p=.02)$. Stereotypy scores from the castrated male population were greater than the shams $(\mathrm{F}(3,199)=$ $3.99, p=.05)$. Cocaine increased horizontal activity $(\mathrm{F}(3,199)=90, p<.001)$ and stereotypy $(\mathrm{F}(3,199)=85$, $p<.001)$ in both castrated and sham-operated males. Unlike ovariectomy, castration did not significantly alter horizontal activity when the $10 \mathrm{mg} / \mathrm{kg}$ cocaine data were considered separately (t-test, $p=.4$ ).

\section{DISCUSSION}

The present study reports robust sex differences in open-field behavioral responses to acute cocaine administration in rats. Cocaine consistently increased motor activity and stereotypy more in female than male rats. Gonadectomy studies indicated a complex relationship between organizational and activational effects of gonadal steroids in mediating these robust sex differences. Of the three behavioral indices measured, horizontal activity was least affected by gonadectomy and vertical activity was most affected. Population analysis of gonadectomy effects proved instrumental for detecting modest activational effects of gonadal hormones on horizontal activity and isolated a novel interaction of vaginal lavage and ovariectomy on cocaine-stimulated activity.

The present behavioral results are consistent with previous reports of enhanced responses of female rats to amphetamine (Robinson et al. 1980, 1982; Becker et al. 1982). Although more amphetamine reaches the brain of female rats (Becker et al. 1982), amphetamine still induces greater locomotor responses in female rats after doses are adjusted to produce the same brain concentrations (Robinson et al. 1980; Becker et al. 1982). In contrast to amphetamine, the present sex differences in cocaine effects are not explained by pharmacokinetic differences. This laboratory previously reported that plasma and brain concentrations of cocaine are the same in male and female rats following i.p. injection (Bowman et al. 1999). Furthermore, the same study showed that ovariectomy and castration did not affect plasma and brain cocaine concentrations. The sex differences in behavioral responses to amphetamine and cocaine suggest these effects may result from basic sex differences in their neural targets, most likely the dopamine system.

Different behavioral topographies are mediated by different brain regions, neurotransmitters, and interactions of neurotransmitters (Randrup and Munkvad 1974; Kelly 1977). Furthermore, different doses of stimulant drugs selectively induce certain behavioral topographies (Sharp et al. 1987; Walker et al. 1990). The current work shows that ovarian hormones selectively modulate certain aspects of the sex differences in co- 
caine-stimulated open-field behavior. Ovariectomy decreased vertical activity relative to female shams but did not affect horizontal activity or stereotypy in the single gonadectomy experiment (Figure 3 ). However, in the population analysis of $10 \mathrm{mg} / \mathrm{kg}$ cocaine data (with greater statistical power), ovariectomy did decrease horizontal activity. The robust effects on rearing and the more limited effects on horizontal activity suggest that ovarian hormones have varying effects on different components of motor behavior.

The population analysis revealed an important source of variability in detecting ovariectomy effects on horizontal activity. The attenuation of cocaine-stimulated horizontal activity in the whole population of ovariectomized rats was due to a subset of animals that had not been vaginally lavaged. Cocaine-stimulated horizontal activity in ovariectomized, lavaged rats was not different than sham, lavaged rats. Relative distributions of horizontal activity values in non-lavaged rats seemed to indicate ovariectomy selectively attenuated a high responding sub-population. An effect of ovariectomy on cocaine-stimulated vertical activity (Figure 3) was detected suggesting a varying effect of lavage on different topographies. Although the mechanism for this effect of vaginocervical stimulation is unknown, these findings suggest that the impact of lavage must be considered in future behavioral studies of psychostimulant effects in rats.

The present results concur with other reports showing that ovariectomy did not affect cocaine-stimulated stereotypy. van Luijtelaar et al. (1996) found that sham and ovariectomized females were equally likely to engage in cocaine-stimulated stereotyped behavior and at a greater rate than intact but not castrated males. Additionally, Sircar and Kim (1999) found no difference in behavioral ratings between sham and ovariectomized females in response to acute injection of $15 \mathrm{mg} / \mathrm{kg}$ cocaine. Camp and Robinson (1988b) have reported that ovariectomy did not affect stereotypy following acute administration of amphetamine. Thus, unlike the neural substrate(s) that mediate(s) cocaine-stimulated hyperactivity, the substrate mediating cocaine-stimulated stereotypy does not respond to loss of ovarian hormones. The possible effect of vaginal lavage on cocainestimulated stereotypy has not been addressed, but would appear to be minimal in light of these numerous references showing a lack of ovariectomy effect on stimulant-induced activity.

The effects of testicular hormones on cocaine-stimulated motor behavior are more straightforward than those of ovarian hormones. Testosterone exerted a slight but consistent inhibitory effect on all cocainestimulated behaviors. In the single gonadectomy experiment (Figure 3) castration increased vertical activity and stereotypy rating relative to male shams. Castration of males had a more modest effect than ovariec- tomy on horizontal activity. Although the individual experiment showed no effect of castration on horizontal activity, the combination of all dose-response data indicated a main effect of castration on horizontal activity. Thus, it appears that activational effects of testosterone are much more involved with vertical activity and stereotypy than horizontal activity, again suggesting differential involvement in this case, of testosterone, on specific behavioral topographies.

The present study, the first investigation of male gonadal hormone effects on cocaine-stimulated activity, is concordant with analogous work with amphetamine. Forgie and Stewart (1994) have shown that castration increased the locomotor response to acute amphetamine, although the effect dissipated with repeated exposure. Another study found no effect of castration on amphetamine-stimulated horizontal activity (Menniti and Baum 1981). Similar to the present results, Dluzen et al. (1986) found that castration increased amphetamine-stimulated rearing behavior. Adult castration increased the duration of stereotyped behavior in response to injection of $5 \mathrm{mg} / \mathrm{kg}$ amphetamine (Beatty et al. 1982). This same study found that exogenous testosterone decreased stereotypy in castrated males and ovariectomized females. Thus, these previous studies of amphetamine-stimulated behaviors are similar to the present results with cocaine, in that adult castration increased stereotypy and vertical activity; effects on horizontal activity were more modest.

The present results and others suggest that activational effects of gonadal hormones explain part but not all of the sex differences in both basal and cocaine-stimulated activity. Gonadal hormones also appear to have organizational effects on open field behaviors in rodents (Beatty 1979). Castration before 30 days of age increases ambulation and rearing to female levels (Scouten et al. 1975; Bengelloun et al. 1976). Female rats injected with testosterone neonatally or at puberty exhibited less ambulation and rearing than oil treated females (Stevens and Goldstein 1983). Likewise, ovariectomy of female rats at one or eight days of age, but not at 23 days or later, reduced activity of adult animals in the open field. Thus, both organizational and activational effects of gonadal hormones play certain roles in mediating the robust sex differences in cocaine-stimulated open-field behavior described in the present studies.

The high responding female subpopulation described in the present work is reminiscent of a previous report of individual differences in amphetamine sensitization described in male rats (Robinson 1988). Hooks and coworkers (1991) have reported that the most active male rats in a novel environment (high responders) exhibit more horizontal activity following cocaine administration. A high responder was defined as having an activity score above the median. Our data clearly 
show that female populations had more high responders than males. These populations of horizontal activity values from all intact female rats had significantly skewed distributions following saline and cocaine administration, suggesting that cocaine might have accentuated a predisposition to increased horizontal activity inherent in females. We will investigate whether this predisposition for high responding is related to the estrous cycle. The three clusters of horizontal activity values from sham, non-lavaged rats in Figure 5A tantalizingly suggest just such a distribution by estrous cycle stage.

Many aspects of dopaminergic function are regulated by gonadal steroids (van Hartesveldt and Joyce 1986) and could contribute to the observed sex difference in cocaine-stimulated behavior. Rivest et al. (1995) reported a sex difference in the density of dopamine transporters with a greater $B_{\max }$ in female than male rats. Estradiol administration increases dopamine receptor density over the course of several days (Hruska 1986; Hruska and Nowak 1988). Physiological doses of estradiol rapidly shift striatal $\mathrm{D}_{2}$ receptors from high to low affinity states (Levesque and Di Paolo 1988; Di Paolo et al. 1988). Ovarian hormones increase striatal dopamine turnover (Di Paolo et al. 1985) and dopamine release (van Hartesveldt and Joyce 1986; Dluzen and Ramirez 1990; Peris et al. 1991; McDermott 1993) and amphetamine-stimulated dopamine release (Becker and Ramirez 1980; Becker and Beer 1986). This laboratory reported that the rates for both dopamine uptake and release in the striatum of naïve female rats are significantly higher than in males (Walker et al. 2000). This result suggests that sex differences in extracellular dopamine regulation may mediate the observed sex differences in saline-stimulated horizontal activity in our populations. Furthermore, different kinetics of extracellular dopamine regulation lead to differential disruption by cocaine, producing the increased behavioral responses to cocaine in female rats (Walker and Kuhn 1997). We believe this is a plausible mechanism to explain sex differences in stimulant responsivity.

In summary, the present results show that females exhibit substantially greater motor responses to cocaine and that gonadal steroids contribute to these differences. The present studies attempted to define the relative magnitudes of sex and gonadal hormone effects on cocaine-stimulated motor behavior in rats. An emerging clinical database suggests that stimulant addictions in men and women have different natural histories and may require different therapies. Development of preventive and therapeutic strategies for drug abuse requires better understanding of sex differences in biologic substrates of drug use and addiction. The present results show that both current gonadal steroid state and underlying sex differences influence behavioral responses to cocaine in the rat.

\section{ACKNOWLEDGMENTS}

This work was supported by grant DA09079 to CMK.

\section{REFERENCES}

Beatty WW (1979): Gonadal hormones and sex differences in nonreproductive behaviors in rodents: Organizational and activational influences. Hormones Behav 12:112163

Beatty WW, Dodge AM, Traylor KL (1982): Stereotyped behavior elicited by amphetamine in the rat: Influences of the testes. Pharmacol Biochem Behav 16:565-568

Becker JB, Beer ME (1986): The influence of estrogen on nigrostriatal dopamine activity: Behavioral and neurochemical evidence for both pre- and postsynaptic components. Behav Brain Res 19:27-33

Becker JB, Cha JH (1989): Estrous cycle-dependent variation in amphetamine-induced behaviors and striatal dopamine release assessed with microdialysis. Behav Brain Res 35:117-125

Becker JB, Ramirez VD (1980): Sex differences in the amphetamine stimulated release of catecholamines from rat striatal tissue in vitro. Brain Res 204:361-372

Becker JB, Robinson TE, Lorenz KA (1982): Sex differences and estrous cycle variations in amphetamine- elicited rotational behavior. Eur J Pharmacol 80:65-72

Bengelloun WA, Nelson DJ, Zent HM, Beatty WW (1976): Behavior of male and female rats with septal lesions: Influence of prior gonadectomy. Physiol Behav 16:317330

Bowman BP, Kuhn CM (1996): Age-related differences in the chronic and acute response to cocaine in the rat. Dev Psychobiol 29:597-611

Bowman BP, Vaughan SR, Walker QD, Davis SL, Little PJ, Scheffler NM, Thomas BF, Kuhn CM (1999): Effects of sex and gonadectomy on cocaine metabolism in the rat. J Pharmacol Exp Ther 290:1316-1323

Cailhol S, Mormede P (1999): Strain and sex differences in the locomotor response and behavioral sensitization to cocaine in hyperactive rats. Brain Res 842:200-205

Camp DM, Becker JB, Robinson TE (1986): Sex differences in the effects of gonadectomy on amphetamine-induced rotational behavior in rats. Behav Neural Biol 46:491495

Camp DM, Robinson TE (1988a): Susceptibility to sensitization. I. Sex differences in the enduring effects of chronic D-amphetamine treatment on locomotion, stereotyped behavior and brain monoamines. Behav Brain Res 30:55-68

Camp DM, Robinson TE (1988b): Susceptibility to sensitization. II. The influence of gonadal hormones on enduring changes in brain monoamines and behavior produced by the repeated administration of $\mathrm{d}$-amphetamine or restraint stress. Behav Brain Res 30:69-88

Cooper RL, Goldman JM, Vandenbergh JG (1993): Monitoring of estrus cyclicity in the laboratory rodent by vaginal lavage. In Chapin RE, Heindel JJ (eds), Reproductive toxicology, Vol 3B. Methods in Toxicol- 
ogy, Female Reproductive Systems. Orlando, FL, Academic Press, pp 45-56

Craft RM, Stratman JA (1996): Discriminative stimulus effects of cocaine in female versus male rats. Drug Alcohol Depend 42:27-37

Di Paolo T, Falardeau P, Morissette M (1988): Striatal D-2 dopamine agonist binding sites fluctuate during the rat estrous cycle. Life Sci 43:665-672

Di Paolo T, Rouillard C, Bedard P (1985): 17 beta-Estradiol at a physiological dose acutely increases dopamine turnover in rat brain. Eur J Pharmacol 117:197-203

Dluzen DE, Green MA, Ramirez VD (1986): The effect of hormonal condition on dose-dependent amphetamine-stimulated behaviors in the male rat. Horm Behav 20:1-6

Dluzen DE, Ramirez VD (1990): In vitro progesterone modulation of amphetamine-stimulated dopamine release from the corpus striatum of ovariectomized estrogentreated female rats: Response characteristics. Brain Res 517:117-122

Forgie ML, Stewart J (1994): Six differences in the locomotoractivating effects of amphetamine: Role of circulating testosterone in adulthood. Physiol Behav 55:639-644

Griffin ML, Weiss RD, Mirin SM, Lange U (1989): A comparison of male and female cocaine abusers. Arch Gen Psychiatry 46:122-126

Haertzen CA, Kocher TR, Miyasato K (1983): Reinforcements from the first drug experience can predict later drug habits and/or addiction: results with coffee, cigarettes, alcohol, barbiturates, minor and major tranquilizers, stimulants, marijuana, hallucinogens, heroin, opiates and cocaine. Drug Alcohol Depend 11:147-165

Haney M, Castanon N, Cador M, Le Moal M, Mormede P (1994): Cocaine sensitivity in Roman High and Low Avoidance rats is modulated by sex and gonadal hormone status. Brain Res 645:179-185

Hooks MS, Jones GH, Smith AD, Neill DB, Justice JB Jr (1991): Response to novelty predicts the locomotor and nucleus accumbens dopamine response to cocaine. Synapse 9:121-128

Hruska RE (1986): Elevation of striatal dopamine receptors by estrogen: dose and time studies. J Neurochem 47:1908-1915

Hruska RE, Nowak MW (1988): Estrogen treatment increases the density of D1 dopamine receptors in the rat striatum. Brain Res 442:349-350

Kelly PH (1977): Drug-induced motor behaviour. In Iverson LL, Iversen SD, Snyder SH (eds), Handbook in Psychopharmacology, Eighth Edition. New York, Plenum Press, pp 295-332

Kosten TA, Gawin FH, Kosten TR, Rounsaville BJ (1993): Gender differences in cocaine use and treatment response. J Subst Abuse Treat 10:63-66

Kosten TR, Kosten TA, McDougle CJ, Hameedi FA, McCance EF, Rosen MI, Oliveto AH, Price LH (1996): Gender differences in response to intranasal cocaine administration to humans. Biol Psych 39:147-148

Levesque D, Di Paolo T (1988): Rapid conversion of high into low striatal D2-dopamine receptor agonist binding states after an acute physiological dose of 17 beta-estradiol. Neurosci Lett 88:113-118
Long J, Evans HM (1922): The Oestrous Cycle in the Rat and Its Associated Phenomena. Berkeley, CA, University of California Press

Lukas SE, Sholar M, Lundahl LH, Lamas X, Kouri E, Wines JD, Kragie, L, Mendelson JH (1996): Sex differences in plasma cocaine levels and subjective effects after acute cocaine administration in human volunteers. Psychopharmacology 125:346-354

McDermott JL (1993): Effects of estrogen upon dopamine release from the corpus striatum of young and aged female rats. Brain Res 606:118-125

Mendelson JH, Weiss R, Griffin M, Mirin SM, Teoh SK, Mello NK, Lex BW (1991): Some special considerations for treatment of drug abuse and dependence in women. NIDA Res Monogr 106:313-327

Menniti FS, Baum MJ (1981): Differential effects of estrogen and androgen on locomotor activity induced in castrated male rats by amphetamine, a novel environment, or apomorphine. Brain Res 216:89-107

Peris J, Decambre N, Coleman-Hardee ML, Simpkins JW (1991): Estradiol enhances behavioral sensitization to cocaine and amphetamine-stimulated striatal [3H]dopamine release. Brain Res 566:255-264

Quinones-Jenab V, Ho A, Schlussman SD, Franck J, Kreek MJ (1999): Estrous cycle differences in cocaine-induced stereotypic and locomotor behaviors in Fischer rats. Behav Brain Res 101:15-20

Randrup A, Munkvad I (1974): Pharmacology and physiology of stereotyped behavior. J Psychiatr Res 11:1-10

Rivest R, Falardeau P, Di Paolo T (1995): Brain dopamine transporter: gender differences and effect of chronic haloperidol. Brain Res 692:269-272

Robbins SJ, Ehrman RN, Childress AR, O'Brien CP (1999): Comparing levels of cocaine cue reactivity in male and female outpatients. Drug Alcohol Depend 53:223-230

Robinson TE (1988): Stimulant drugs and stress: factors influencing individual differences in the susceptibility to sensitization. In Kalivas PW, Barnes C (eds), Sensitization in the Nervous System. Caldwell, NJ, Telford Press, pp 145-173

Robinson TE, Becker JB, Ramirez VD (1980): Sex differences in amphetamine-elicited rotational behavior and the lateralization of striatal dopamine in rats. Brain Res Bull 5:539-545

Robinson TE, Camp DM, Becker JB (1981): Gonadectomy attenuates turning behavior produced by electrical stimulation of the nigrostriatal dopamine system in female but not male rats. Neurosci Lett 23:203-208

Robinson TE, Camp DM, Jacknow DS, Becker JB (1982): Sex differences and estrous cycle dependent variation in rotational behavior elicited by electrical stimulation of the mesostriatal dopamine system. Behav Brain Res $6: 273-287$

Savageau MM, Beatty WW (1981): Gonadectomy and sex differences in the behavioral responses to amphetamine and apomorphine of rats. Pharmacol Biochem Behav 14:17-21

Schneider BF, Norton S (1979): Circadian and sex differences in hyperactivity produced by amphetamine in rats. Physiol Behav 22:47-51 
Scouten CW, Grotelueschen LK, Beatty WW (1975): Androgens and the organization of sex differences in active avoidance behavior in the rat. J Comp Physiol Psychol 88:264-270

Sershen H, Hashim A, Lajtha A (1998): Gender differences in kappa-opioid modulation of cocaine-induced behavior and NMDA-evoked dopamine release. Brain Res 801:67-71

Sharp T, Zetterstrom T, Ljungberg T, Ungerstedt U (1987): A direct comparison of amphetamine-induced behaviours and regional brain dopamine release in the rat using intracerebral dialysis. Brain Res 401:322-330

Sircar R, Kim D (1999): Female gonadal hormones differentially modulate cocaine-induced behavioral sensitization in Fischer, Lewis, and Sprague-Dawley rats. J Pharmacol Exp Ther 289:54-65

Stevens R, Goldstein R (1983): Organisational effects of neonatal and pubertal testosterone on sexually differentiated behaviours in the open-field and head-dip apparatus. Q J Exp Psychol 35(1):81-92

van Haaren F, Meyer ME (1991): Sex differences in locomo- tor activity after acute and chronic cocaine administration. Pharmacol Biochem Behav 39:923-927

van Hartesveldt C, Joyce JN (1986): Effects of estrogen on the basal ganglia. Neurosci Biobehav Rev 10:1-14

van Luijtelaar ELJM, Dirksen R, Vree TB, van Haaren F (1996): Effects of acute and chronic cocaine administration on EEG and behaviour in intact and castrated male and intact and ovariectomized female rats. Brain Res Bull 40:43-50

Walker QD, Kuhn CM (1997): In vivo dopamine release is greater in female than male rats using fast-scan cyclic voltammetry. Soc Neurosci Abstr 23:693

Walker QD, Lewis MH, Crofton KM, Mailman RB (1990): Triadimefon, a triazole fungicide, induces stereotyped behavior and alters monoamine metabolism in rats. Toxicol Appl Pharmacol 102:474-485

Walker QD, Rooney MB, Wightman RM, Kuhn CM (2000): Dopamine release and uptake are greater in female than male rat striatum as measured by fast cyclic voltammetry. Neuroscience 95:1061-1070 